\title{
Hypothyroidism Causing Pericardial Effusion: A Case Report
}

\author{
Sabawoon Mirwais ${ }^{1}$, Syed Hassan Kazmi ${ }^{1}$, Syed I. Hussain ${ }^{2}$, Maiwand Mirwais ${ }^{3}$, Ajay Sharma ${ }^{3}$ \\ 1. Cardiovascular Medicine, Beth Israel Deaconess Medical Center, Boston, USA 2. Internal Medicine, University of \\ Pittsburgh Medical Center Mercy, Pittsburgh, USA 3. Cardiology, Lahey Hospital and Medical Center, Burlington, USA
}

Corresponding author: Sabawoon Mirwais, sabawoonuhs@gmail.com

\begin{abstract}
Hypothyroidism is an endocrine disorder with worldwide prevalence that can affect multiple organ systems. It can be asymptomatic and subclinical or overtly symptomatic with a potential to get complicated by fatal pathologies. It is an established cause of pericardial effusion, which in turn can be complicated by cardiac tamponade and severe hemodynamic instability. Herein we report the case of a 68-year-old male with history of Graves' disease treated with radioiodine ablation and consequent hypothyroidism, presenting with moderate pericardial effusion.
\end{abstract}

Categories: Cardiology, Endocrinology/Diabetes/Metabolism, Internal Medicine

Keywords: hypothyroidism, pericardial effusion

\section{Introduction}

Hypothyroidism, an endocrine disorder characterized by low or absent functional thyroid hormone, is diagnosed when decreased levels of thyroid hormones cause an increased secretion of thyroid-stimulating hormone (TSH) [1]. The clinical picture of hypothyroidism can have variable presentation, ranging from absent and subclinical symptoms to overt multiorgan failure. The clinical manifestations can vary based on the age of the patient at the time of diagnosis and the severity of hormone deficiency. The most commonly reported symptoms of hypothyroidism are weight gain, constipation, cold sensitivity, fatigue, and dry skin [2-4]. Less common signs include myopathy, carpal tunnel syndrome, and hoarseness of voice. Hypothyroidism, having the potential to affect any organ system, can be complicated by serious pathologies requiring timely intervention. One of the rare, yet serious complications of hypothyroidism is pericardial effusion [5-10]. Hypothyroidism causes increased permeability of the pericardial capillaries to albumin.This, in addition to decreased drainage of albumin into the lymphatic system, leads to increased colloid pressure within the pericardium and hence, decreased colloid osmotic pressure gradient between the pericardial space and pericardium. This culminates in the accumulation of fluid in the pericardial space [11-14]. The resultant pericardial effusion can be subclinical and can progress to an overt pathology.

Received 11/14/2019

Review began 12/09/2019 Review ended 12/12/2019 Published 12/16/2019

\section{() Copyright 2019}

Mirwais et al. This is an open access article distributed under the terms of the Creative Commons Attribution License CC-BY 3.0., which permits unrestricted use, distribution, and reproduction in any medium, provided the original author and source are credited.

\section{Case Presentation}

A 68-year-old male with an extensive medical history of alcohol and tobacco use, medication noncompliance, Graves' disease treated with radioiodine ablation and resulting hypothyroidism, chronic obstructive pulmonary disease, hypertension, deep venous thrombosis with inferior vena cava filter placement, and bipolar disorder presented to the emergency room with alcohol intoxication and cough. The patient also reported subjective fever and chills at the time of presentation along with history of previous incarceration, shelter living, and homelessness. His initial chest x-ray showed probable pericardial effusion, which was later confirmed on chest CT scan (Figure 1) and bedside echocardiography (Figure 2). Chest CT scan also showed ground glass opacities in the bilateral lower lobes. The evaluation of patient's presenting complaint of cough guided the way for the incidental finding of pericardial effusion on chest $x$-ray. Bedside ultrasound in the emergency room ruled out right ventricular collapse. Transthoracic echocardiography demonstrated early tamponade physiology, and the patient was hemodynamically stable. Based on the presentation, we suspected tuberculosis (TB) as the cause of his chronic cough. The patient was transferred to a negative pressure room for infectious evaluation. TB was ruled out after a negative purified protein derivative and QuantiFERON gold test. He was instead found to have been suffering from aspiration pneumonia after his sputum culture came back positive for Klebsiella and Serratia extended-spectrum betalactamase producing species. Poor dentition and usual alcohol intoxication made the patient at risk of recurrent aspiration of the oral bacteria. 


\section{Cureus}

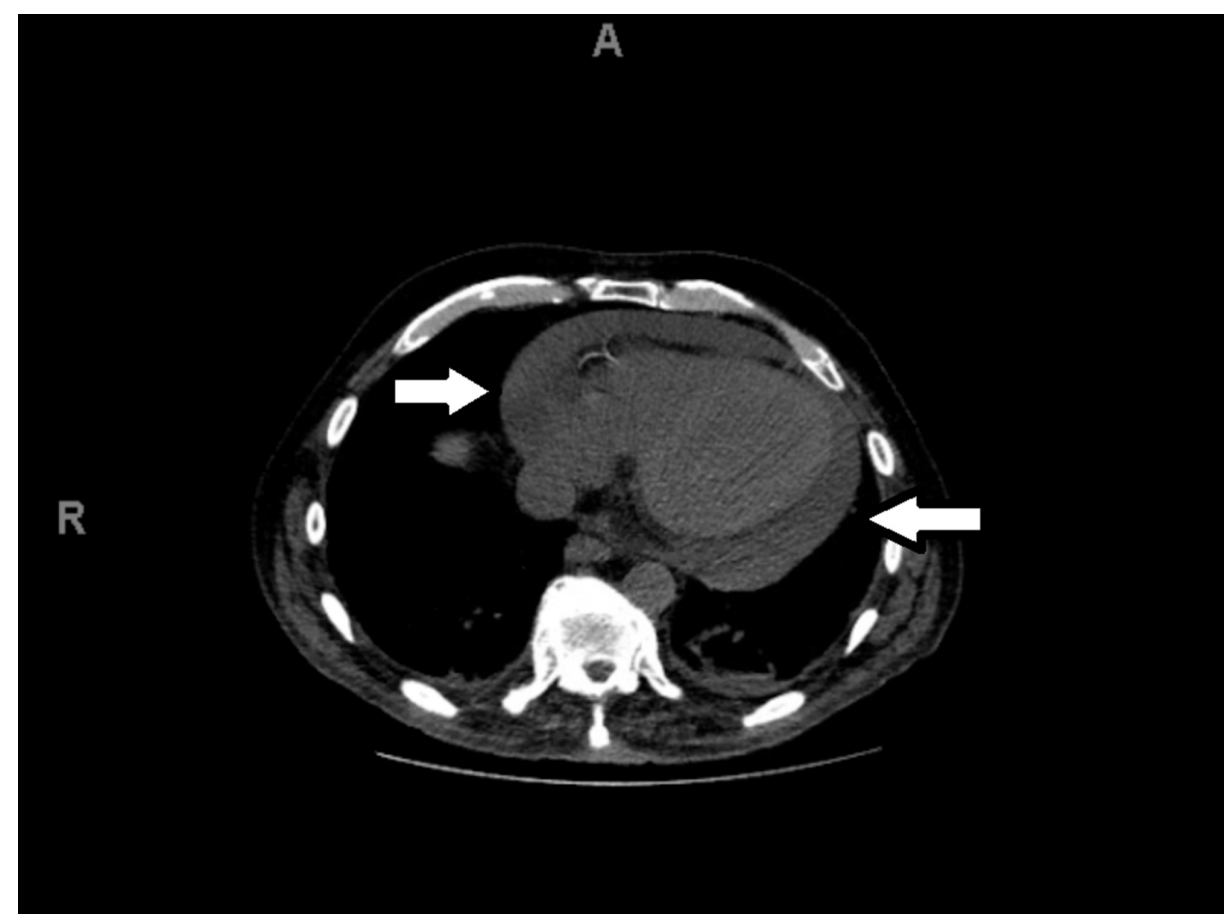

FIGURE 1: CT scan.

Image demonstrating pericardial effusion (white arrows).

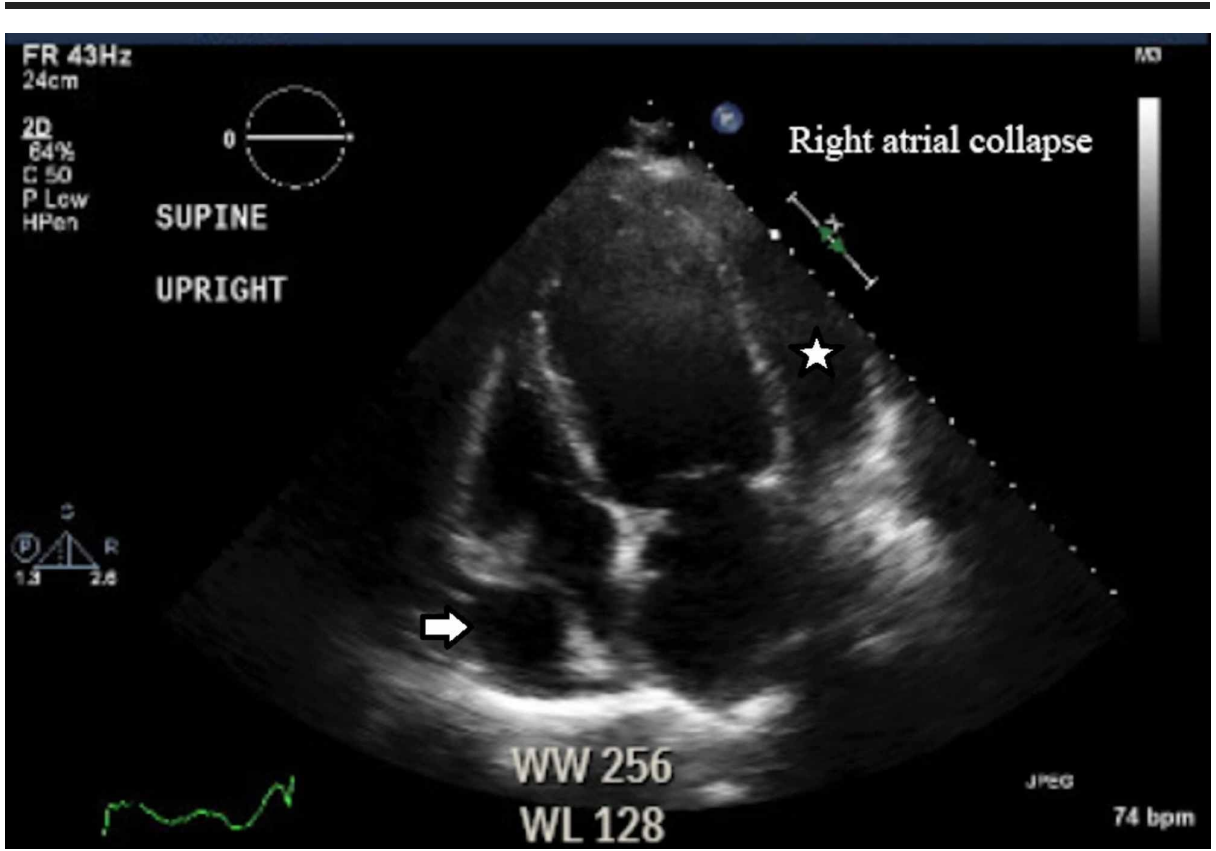

FIGURE 2: Echocardiogram.

Image shows pericardial effusion (white star) and right atrial collapse (white arrow).

The patient was prescribed levothyroxine $25 \mathrm{mcg}$ daily for hypothyroidism in the past but he had run out of his medication several months ago. His TSH level of $31.42 \mu \mathrm{IU} / \mathrm{mL}$ (normal range: 0.4-5.5 $\mu \mathrm{IU} / \mathrm{mL}$ ) with undetectable free $\mathrm{T} 4$ and previous history of thyroid disease pointed towards uncontrolled hypothyroidism as the likely cause of his moderate pericardial effusion. The patient's hemodynamic stability did not qualify him for the indication of pericadiocentesis. He was prescribed levothyroxine $150 \mathrm{mcg}$ daily which resulted in the reduction of the TSH level to $14.17 \mu \mathrm{IU} / \mathrm{mL}$ in less than two weeks. The pericardial effusion was followed up with serial transthoracic echocardiogram, and the patient was discharged on the advice to follow-up with primary care physician. 


\section{Discussion}

Our patient was suffering from multiple comorbidities at the time of presentation. His extensive medical history and unconventional presentation delayed the diagnosis of hypothyroidism as the cause of moderate pericardial effusion. Shelter living, homelessness, history of incarceration, subjective fever and chills, presenting complaint of chronic cough, and the fact that differential diagnoses of pericardial effusion include TB, led the team to suspect and provisionally diagnose pulmonary TB $[15,16]$. Also, with an extended medical history, our patient required urgent multidisciplinary approach. Patient's history of previous thyroid disease and thyroid function test results established the diagnosis of hypothyroidism. Metabolic disorders, such as hypothyroidism, are considered one of the less common causes of pericardial effusion [17]. Most of the clinical symptoms of hypothyroidism can easily be reversed with thyroid hormone replacement [18]. The relatively high incidence of pericardial effusion due to hypothyroidism and the potential complications of pericardial effusion necessitate early recognition and management $[6,8,9,19]$. The rarity of the association between these two conditions warrants more research and investigation in order to be well prepared to provide the standard of care.

\section{Conclusions}

Hypothyroidism with pericardial effusion is a relatively rare occurrence in clinical setting. The potential of this presentation to be complicated by life-threatening conditions, such as cardiac tamponade and hemodynamic instability, requires a high degree of clinical suspicion. Thyroxine therapy over extended period can result in alleviating mild pericardial effusion and serial echocardiography can aide in documenting the effect of treatment and change in the volume of effusion.

\section{Additional Information \\ Disclosures}

Human subjects: Consent was obtained by all participants in this study. Conflicts of interest: In compliance with the ICMJE uniform disclosure form, all authors declare the following: Payment/services info: All authors have declared that no financial support was received from any organization for the submitted work. Financial relationships: All authors have declared that they have no financial relationships at present or within the previous three years with any organizations that might have an interest in the submitted work. Other relationships: All authors have declared that there are no other relationships or activities that could appear to have influenced the submitted work.

\section{References}

1. Udovcic M, Pena RH, Patham B, Tabatabai L, Kansara A: Hypothyroidism and the heart. Methodist Debakey Cardiovasc J. 2017, 13:55-59. 10.14797/mdcj-13-2-55

2. Carle A, Pedersen IB, Knudsen N, Perrild H, Ovesen L, Laurberg P: Hypothyroid symptoms and the likelihood of overt thyroid failure: a population-based case-control study. Eur J Endocrinol. 2014, 171:593602. 10.1530/EJE-14-0481

3. Diaz A, Lipman Diaz EG: Hypothyroidism. Pediatr Rev. 2014, 35:336-347. 10.1542/pir.35-8-336

4. Samuels MH: Psychiatric and cognitive manifestations of hypothyroidism. Curr Opin Endocrinol Diabetes Obes. 2014, 21:377-383. 10.1097/MED.0000000000000089

5. Chahine J, Ala CK, Gentry JL, Pantalone KM, Klein AL: Pericardial diseases in patients with hypothyroidism . Heart. 2019, 105:1027-1033. 10.1136/heartinl-2018-314528

6. Kabadi UM, Kumar SP: Pericardial effusion in primary hypothyroidism . Am Heart J. 1990, 120:1393-1395. 10.1016/0002-8703(90)90253-t

7. Hardisty CA, Naik DR, Munro DS: Pericardial effusion in hypothyroidism. Clin Endocrinol. 1980, 13:349-354. 10.1111/j.1365-2265.1980.tb03395.x

8. Kerber RE, Sherman B: Echocardiographic evaluation of pericardial effusion in myxedema. Incidence and biochemical and clinical correlations. Circulation. 1975, 52:823-827. 10.1161/01.cir.52.5.823

9. Nouh MS, Famuyiwa OO, Sulimani RA, Al-Nuaim A: The spectrum of echocardiographic abnormalities in hypothyroidism and the effect of hormonal treatment. Ann Saudi Med. 1991, 11:611-615. 10.5144/02564947.1991.611

10. Rawat B, Satyal A: An echocardiographic study of cardiac changes in hypothyroidism and the response to treatment. Kathmandu Univ Med J (KUMJ). 2004, 2:182-187.

11. Vogiatzidis K, Zarogiannis SG, Aidonidis I, et al.: Physiology of pericardial fluid production and drainage . Front Physiol. 2015, 6:62. 10.3389/fphys.2015.00062

12. Yamanaka S, Kumon Y, Matsumura Y, Kamioka M, Takeuchi H, Sugiura T: Link between pericardial effusion and attenuation of QRS voltage in patients with hypothyroidism. Cardiology. 2010, 116:32-36. 10.1159/000313464

13. Parving HH, Hansen JM, Nielsen SL, Rossing N, Munck O, Lassen NA: Mechanisms of edema formation in myxedema--increased protein extravasation and relatively slow lymphatic drainage. N Engl J Med. 1979, 301:460-465. 10.1056/NEJM197908303010902

14. Stewart RH, Rohn DA, Allen SJ, Laine GA: Basic determinants of epicardial transudation. Am J Physiol. 1997, 273:H1408-H1414. 10.1152/ajpheart.1997.273.3.H1408

15. Imazio M, Adler Y: Management of pericardial effusion. Eur Heart J. 2013, 34:1186-1197. 10.1093/eurheartj/ehs372

16. Desai HN: Tuberculous pericarditis. A review of 100 cases . S Afr Med J. 1979, 55:877-880.

17. Chou SL, Chern CH, How CK, Wang LM, Huang CI, Lee CH: A rare case of massive pericardial effusion 


\section{Cureus}

secondary to hypothyroidism. J Emerg Med. 2005, 28:293-296. 10.1016/i.jemermed.2004.11.017

18. Redinger RN: The many faces of hypothyroidism: a review of two inpatient populations . J Ky Med Assoc. 2005, 103:149-157.

19. Hidano A, Torikai S, Uemura T, Shimizu S: Malignancy and interstitial pneumonitis as fatal complications in dermatomyositis. J Dermatol. 1992, 19:153-160. 10.1111/j.1346-8138.1992.tb03199.x 